\title{
PENGEMBANGAN APLIKASI MOBILE PADA PELAYANAN PEMERINTAH KOTA YOGYAKARTA DALAM RANGKA TANGGAP RESPON INFORMASI DAN KELUHAN DARI MASYARAKAT
}

\author{
Bambang Yuwono ${ }^{1)}$, Oliver Samuel Simanjuntak ${ }^{2}$, Danny Wijaksono ${ }^{3)}$ \\ ${ }^{1,2,3)}$ Program Studi Teknik Informatika UPN "Veteran" Yogyakarta \\ Jl. Babarsari no 2 Tambakbayan 55281 Yogyakarta Telp (0274)-485323 \\ e-mail : bambangy@gmail.com ${ }^{1)}$, oliver.simanjuntak@upnyk.ac.id ${ }^{2)}$, dannysatriani8@gmail.com ${ }^{3)}$
}

\begin{abstract}
Unit Pelayanan Informasi dan Keluhan (UPIK) is an e-government application built by the Yogyakarta City Government in order. UPIK becomes a container of input information in the form of complaints, questions, information, suggestions, and suggestions from the community, as well as providing solutions response to information that entered the Yogyakarta City government. The goal is to accelerate the service of information and complaints to be conveyed by the public without the need for a convoluted procedure. In its implementation, UPIK has several limitations, such as: updating of news which is not fast, lack of responsiveness of community response or complaint, no coordinate location where community reporting, and delivery of complaints and suggestions from the public through opertator and to the office implemented manually. The methodology used in this study is GRAPPLE (Guidelines for Rapid APPlication Engineering) which is a method commonly used for the development of object-oriented applications. This Android-based application is built using java programming language by utilizing Brute Force method on the system, so that users easier to report complaints to the relevant offices. With this application can help the performance of related agencies responsible for making corrections of complaints that come in the Application Information Services and Complaints Yogyakarta-based mobile community.
\end{abstract}

Keywords: Complaint, Community, Brute Force, Office, Response, Android.

\begin{abstract}
Abstrak
Unit Pelayanan Informasi dan Keluhan (UPIK) adalah sebuah penerapan e-government yang dibangun oleh Pemerintah Kota Yogyakarta dalam rangka. UPIK menjadi wadah informasi masukan berupa keluhan, pertanyaan, informasi, usul, dan saran dari masyarakat, serta memberikan solusi respon atas informasi yang masuk kepemerintah Kota Yogyakarta. Tujuannya adalah untuk mempercepat pelayanan informasi dan keluhan yang ingin disampaikan masyarakat tanpa perlu prosedur yang berbelit belit. Dalam pelaksanaanya, UPIK memiliki beberapa keterbatasan, diantaranya adalah: pemutahiran berita yang tidak cepat, kurang tanggap penyelesaian tanggapan atau pengaduan masyarakat, tidak ada lokasi koordinat tempat pelaporan masyarakat, dan penyampaian keluhan dan saran dari masyarakat melalui opertator dan kepada dinas dilaksanakan secara manual. Metodologi yang digunakan dalam penelitian ini adalah GRAPPLE (Guidelines for Rapid APPlication Engineering) yaitu suatu metode yang lazim digunakan untuk pengembangan aplikasi berorientasi objek. Aplikasi berbasis Android ini dibangun menggunakan bahasa pemprograman java dengan memanfaatkan metode Brute Force pada sistem, agar pengguna lebih mudah untuk melaporkan keluhan ke dinas yang terkait. Dengan aplikasi ini dapat membantu kinerja dinas-dinas terkait yang bertanggung jawab untuk melakukan pembenahan keluhan yang masuk di Aplikasi Pelayanan Informasi dan Pengaduan masyarakat Kota Yogyakarta berbasis mobile.
\end{abstract}

Kata kunci: Keluhan, Masyarakat, Brute Force, Dinas, Respon, Android.

\section{PENDAHULUAN}

1.1 Latar Belakang

Penyediaan layanan informasi dan keluhan masyarakat melalui teknologi mobile menjadi alternatif yang sangat menarik dan penting untuk dikaji karena jika diaplikasikan akan berpotensi besar untuk dapat mengatasi berbagai masalah yang ada di masyarakat (Sembiring, 2006). Pemerintah bekerja sama dengan dinas-dinas yang terkait untuk memenuhi fasilitas yang dibutuhkan masyarakat saat ini khususnya di Kota Yogyakarta. Secara bertahap pemerintah Kota Yogyakarta terus melakukan perbaikan fasilitas publik yang dirasa kurang memadai untuk dipakai. Masyarakat pun akan senang apabila Pemerintah dapat menjalin hubungan yang baik dengan masyarakat, selalu memperhatikan keinginan dari warganya. Namun, belum semua fasilitas publik di kota Yogyakarta ini layak digunakan. Terbukti dengan masih adanya beberapa keluhan yang menyampaikan ketidakpuasannya terhadap penyelenggaraan fasilitas publik di beberapa tempat karena sekarang dianggap sudah tidak layak lagi untuk digunakan. 
Pemerintah Kota Yogyakarta membentuk Unit Pelayanan Informasi dan Keluhan yang selanjutnya disebut UPIK yang menjadi salah satu tugas untuk dikelola oleh bagian hubungan masyarakat dan informasi yang bertujuan untuk mendapatkan informasi masukan berupa keluhan, pertanyaan, informasi, usul, dan saran dari masyarakat, serta memberikan solusi respon atas informasi yang masuk kepemerintah Kota Yogyakarta. Media yang disediakan UPIK yaitu: Short Message Service (SMS), telepon/fax, email, website, dan datang langsung. Namun masih banyak komentar negatif dari aplikasi ini diantaranya, masih kurang update nya berita yang ada di aplikasi ini, melihat kecenderungan konsumsi masyarakat atas tingginya literasi perkembangan teknologi perlu inovasi baru contohnya memakai aplikasi mobile, kurang tanggapnya pemerintah dalam menyelesaikan laporan atau pengaduan yang diberikan masyarakat, tidak ada lokasi koordinat tempat yang dijadikan laporan dari masyarakat, dan operator upik sendiri masih harus menyampaikan keluhan dan saran yang masuk ke dinas yang bersangkutan secara manual. Dari permasalahan diatas dapat disimpulkan bahwa adanya penelitian ini dapat membantu kinerja dinas-dinas terkait yang bertanggung jawab untuk melakukan pembenahan keluhan yang masuk di Aplikasi Pelayanan Informasi dan Pengaduan masyarakat Kota Yogyakarta berbasis mobile, serta bisa memberikan titik lokasi kejadian yang masyarakat ingin laporkan ke dinas yang berkaitan, juga memudahkan masyarakat Kota Yogyakarta dalam memberikan aduannya dengan fitur mesin pencari atau Search engine online yang menggunakan metode Brute Force sehingga masyarakat tidak bingung harus melaporkan ke dinas mana yang berkaitan dengan keluhan tersebut.

\section{TINJAUAN PUSTAKA}

\subsection{Android}

Pada tahun 2005 Google mengakuisi Andorid Inc yang pada saat itu dimotori oleh Andy Robin, Rich Miner, Nick Sears dan Chris White (Juman,2013). Kemudian pada tahun itu juga memulai membangun platform Android secara intensif. Pada tanggal 12 November 2007 Google bersama Open handset Alliance (OHA) yaitu konsorium perangkat mobile terbuka merilis Google Android Software Development Kit (SDK). Android merupakan subset perangkat lunak untuk perangkat mobile yang meliputi sistem operasi, middleware dan aplikasi inti yang dirilis oleh Google. Sedangkan Android SDK menyediakan toolsdan Application Programming Interface(API) yang diperlukan untuk mengembangkan pada platform Android dengan menggunakan bahasa pemrograman Java. Dalam paket sistem operasi android terdiri dari beberapa unsur. Secara sederhana arsitektur android merupakan sebuah kernel Linux dan sekumpulan pustaka $\mathrm{C} / \mathrm{C}++$ dalam suatu framework yang menyediakan dan mengatur alur proses aplikasi. (Google IO, Android Anatomy and Physiology). Pada android tertanam paket pustaka inti yang menyediakan sebagian besar fungsi android. Inilah yang membedakan Android dibandingkan dengan sistem operasi lain yang juga mengimplementasikan Linux. Android Runtime merupakan mesin virtual yang membuat aplikasi android menjadi lebih tangguh dengan paket pustaka yang telah ada. Dalam Android Runtime terdapat 2 bagian utama, yaitu : a) Pustaka inti, dan b) Mesin virtual Dalvik (Nicolas Gramlich, Andbook, anddev.org)

\subsection{Metode Guidelines for Rappid Application Engineering (GRAPPLE)}

GRAPPLE merupakan metodologi yang fleksibel dan memberikan panduan yang jelas dalam proses pengembangan sistem. Metode ini terdiri dari lima bagian yaitu (Schmuller, 1999): a) Requirement gathering. Pada tahap pertama yang dilakukan oleh pengembang perangkat lunak adalah mengambil informasi lengkap dari pengguna tentang sistem yang akan dibangun dengan wawancara dan kuisioner. Wawancara dilakukan langsung dengan pengguna yang menginginkan adanya sistem ini dan dengan pengguna yang berhubungan langsung dengan sistem. Tahap ini menyarankan untuk mewawancarai pengguna yang memiliki kemampuan teknis. Analisis masalah, fungsi dan kebutuhan sistem termasuk dalam tahap requirement gathering. b) Analysis. Di tahap analysis yang dilakukan adalah menggali lebih dalam hasil yang diperoleh dalam tahap sebelumnya. Tahap ini mengkaji permasalahan pengguna dan menganalisis solusinya. Pada tahap ini yang termasuk didalamnya antara lain adalah pengembangan data dan informasi dari requirement gathering serta pembuatan diagram. c) Design. Tahap design dilakukan untuk merancang solusi yang dihasilkan pada tahap analysis dan design dapat berjalan dua arah saling menyesuaikan sampai diperoleh rancangan yang tepat. Pada tahap ini yang termasuk didalamnya adalah diagram yang telah dianalisis serta dibuat rancangannya. d) Development. Tahap ini ditangani oleh pengembang program untuk membangun kode program dan userinterface. Pengujian program dan dokumentasi sistem dilakukan pada tahap ini. e) Deployment. Tahap deployment adalah tahap pendistribusian produk yang dihasilkan kepada pengguna. Tahap ini mencakup instalasi dan perencanaan backup data bila diminta oleh pengguna sesuai dengan perjanjian sebelumnya. 


\subsection{Algoritma Brute Force}

Brute force adalah sebuah pendekatan yang sangat jelas untuk memecahkan suatu persoalan, biasanya didasarkan pada problem statement dan definisi konsep yang dilibatkan. Brute Force merupakan algoritma pencarian string termudah. Dengan asumsi bahwa teks berada di dalam array $\mathrm{T}[1 . . \mathrm{n}]$ dan pattern berada di dalam array P[1..m], maka algoritma Brute Force pencocokan string adalah sebagai berikut ( Munir, 2004) : 1. Mula-mula pattern P dicocokkan pada awal teks T. 2. Dengan bergerak dari kiri ke kanan, bandingkan setiap karakter di dalam pattern $\mathrm{P}$ dengan karakter yang bersesuaian di dalam teks T sampai: - Semua karakter yang dibandingkan cocok atau sama (pencarian berhasil), atau - Dijumpai sebuah ketidakcocokan karakter (pencarian belum berhasil) 3 . Bila pattern $\mathrm{P}$ belum ditemukan kecocokannya dan teks $T$ belum habis, geser pattern $\mathrm{P}$ satu karakter ke kanan dan ulangi langkah 2. Persoalan pencocokan string dapat dirumuskan sebagai berikut: 1 . Teks (text), yaitu (long) string yang panjangnya $\mathrm{n}$ karakter 2. Pattern, yaitu string dengan panjang $\mathrm{m}$ karakter $(m<n)$ yang akan dicari di dalam teks Contoh cara kerja algoritma Brute Force: Pattern : FORMASI Teks : INFO INFORM DIINFORMASIKAN

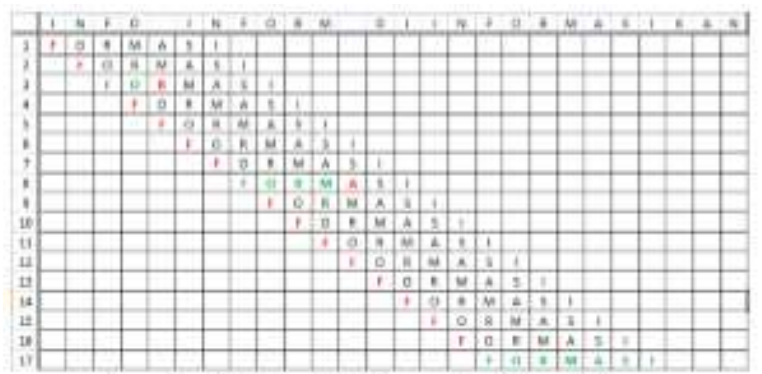

Gambar 1 Contoh Pencarian Brute Force Sumber : bulansabit.blogdetik.com

\section{ANALISIS DAN PERANCANGAN}

\subsection{Arsitektur Sistem}

Pengguna yang sudah memasang aplikasi ini di smartphone dapat langsung mengupload keluhan yang mereka temukan. Gambar 2 merupakan gambaran arsitektur dari aplikasi pengaduan dan pelayanan informasi pemerintah kota Yogakarta. User yang sudah meng-install aplikasi ini, dapat melakukan upload keluhan, melihat lokasi keluhan dengan google maps, dan melihat status keluhan dari smartphone yang berbasis Android. Data yang masuk dapat diolah oleh admin, kemudian keluhan yang masuk akan disimpan di database. Aplikasi ini membutuhkan internet untuk mengambil data dari database.

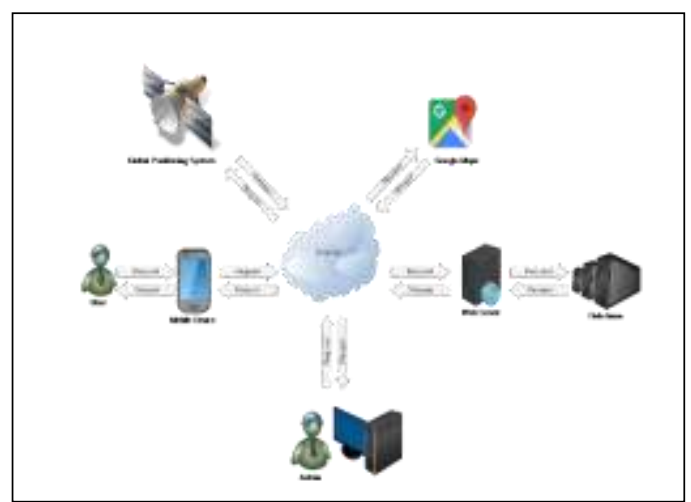

Gambar 2 Arsitektur sistem

\subsection{Analisis Aplikasi}

Dari arsitektur sistem, berikut ini adalah analisis sistem dari aplikasi, terdiri dari Use Case Diagram, Class Diagram, Activity Diagram, dan Sequence Diagram.

\subsubsection{Use Case Diagram}

Pada Use Case dapat dijelaskan terdapat 1 aktor, yaitu masyarakat, Masyarakat dapat melakukan 9 aktifitas atau kegiatan, yaitu registrasi, login, beranda, upload keluhan, melihat keluhan di dinas perhubungan, melihat keluhan di dinas pariwisata dan kebudayaan, melihat keluhan di dinas pemukiman dan prasarana, melihat keluhan anda, dan melihat peta keluhan. Agar bias melakukan 9 aktifitas tersebut user harus login terlebih dahulu. 


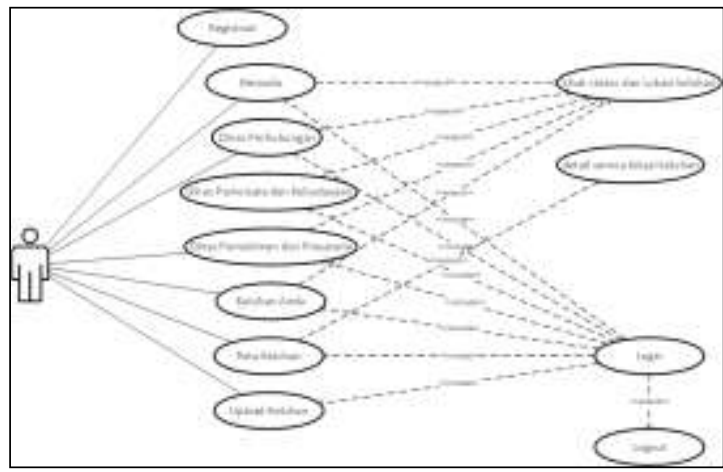

Gambar 3 Use Case Diagram

\subsubsection{Class Diagram}

Class diagram aplikasi mobile pengaduan dan pelayanan informasi pemerintah kota Yogyakarta menggunakan metode brute force berbasis android dapat digambarkan pada Gambar 4.

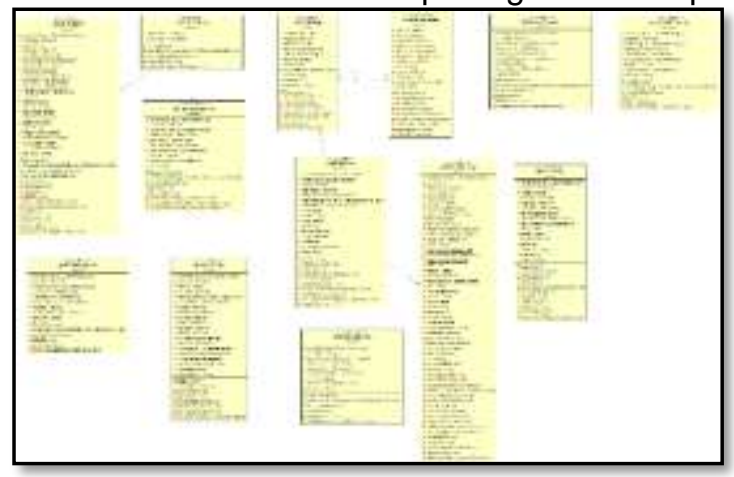

Gambar 4 Class Diagram

\subsubsection{Actifity Diagram}

Actifity diagram dapat dijabarkan menjadi 3 proses, yaitu: proses Login, Upload Keluhan dan Beranfa. Ketiga proses tersebut dapat dilihat pada Gambar 5, 6, dan Gambar 7

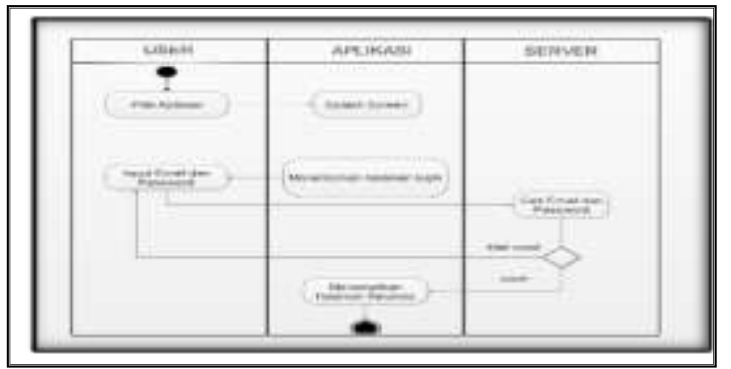

Gambar 5 Actifity Diagram - Proses Login

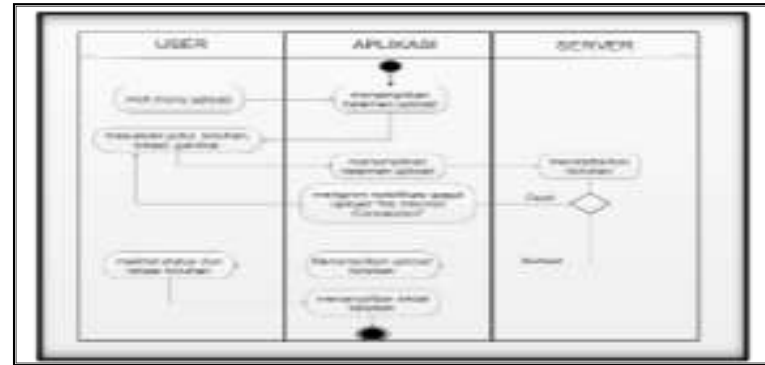

Gambar 6 Actifity Diagram - Proses Upload Keluhan

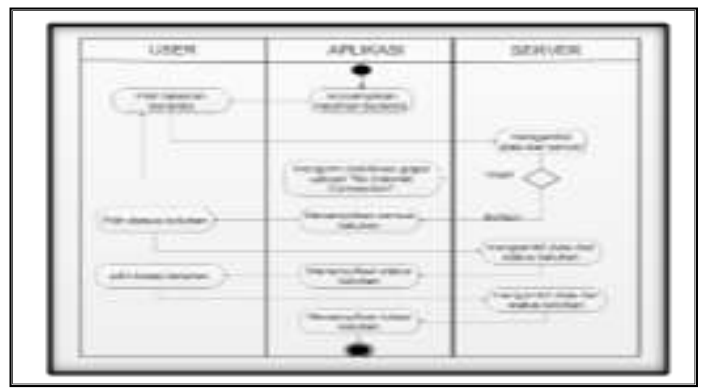

Gambar 7 Actifity Diagram - Proses Beranda

\subsubsection{Sequence Diagram}


Actifity diagram dapat dijabarkan menjadi 3 proses, yaitu: proses Login, Upload Keluhan dan Beranfa. Ketiga proses tersebut dapat dilihat pada Gambar 8, 9, dan Gambar 10

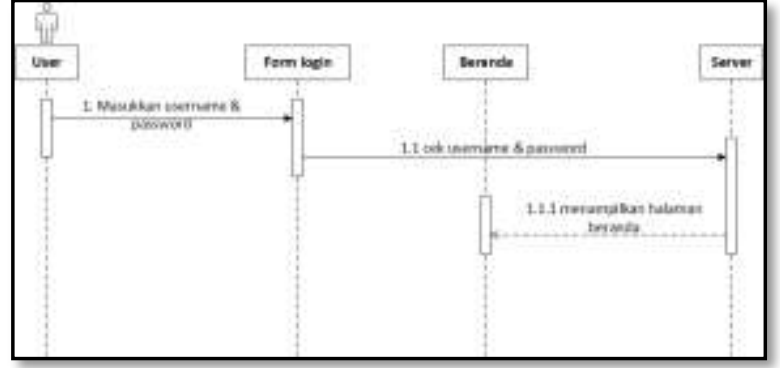

Gambar 8 Sequence Diagram - Proses Login

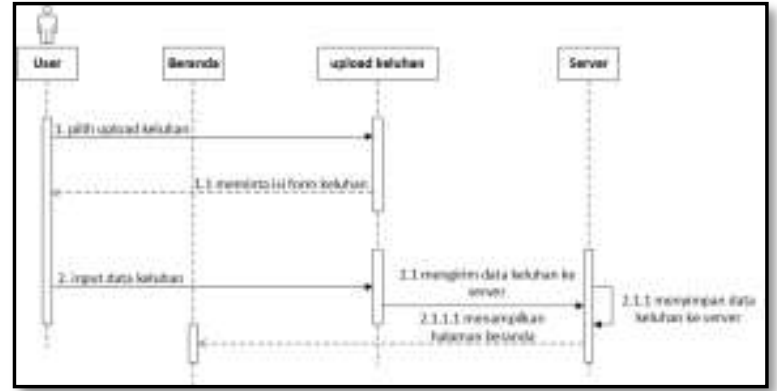

Gambar 9 Sequence Diagram - Proses Upload Keluhan

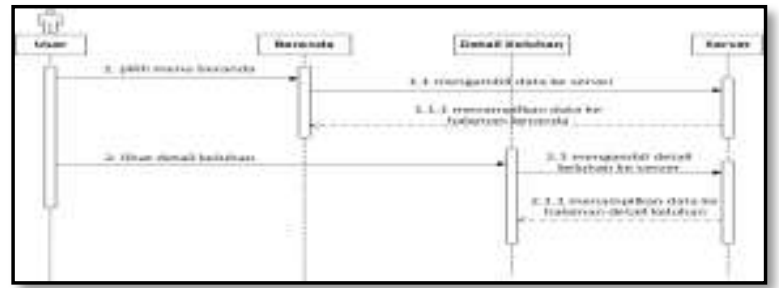

Gambar 10 Sequence Diagram - Proses Beranda

\subsection{Rancangan Basis Data}

Dalam merancang basis data, ada beberapa tahapan yang harus dirancang yaitu perancangan Entitiy Relationship Diagram (ERD) pada Gambar 11 dan perancangan struktur tabel, dan perancangan Relasi Antar Tabel (RAT) pada Gambar 12

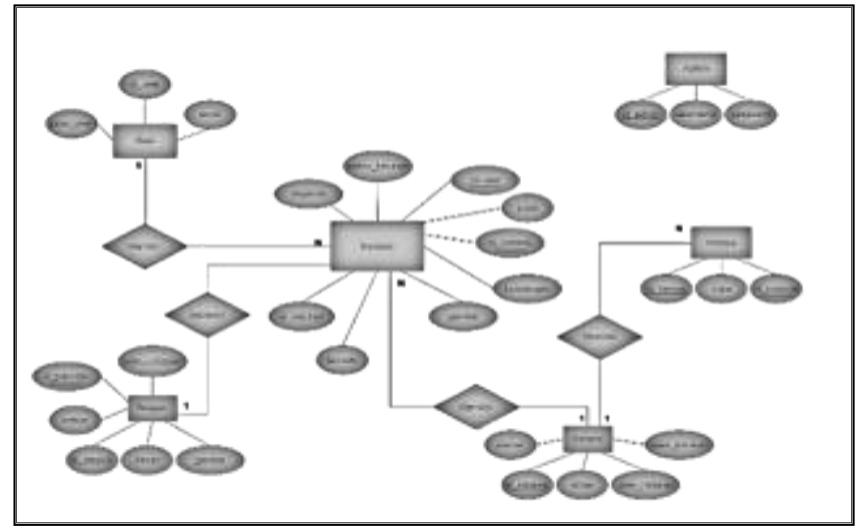

Gambar 11 Entity Relationship Diagram

Untuk memenuhi kebutuhan sistem, maka diperlukan basis data yang dapat menampung seluruh data yang dibutuhkan. Basis data dalam sistem ini terdiri dari beberapa tabel yang masing-masing tabel tersebut dapat dilihat sebagai berikut : a) Tabel Admin. Tabel admin berfungsi untuk menyimpan dan mengakses semua data yang berhubungan dengan admin dan user operator. Yakni berupa hak akses yang digunakan agar masuk ke dalam sebuah sistem. Pada tabel admin memiliki primary key pada id_admin. b) Tabel Instansi. Tabel instansi berfungsi untuk menyimpan data instansi seperti, id_instansi, dinas, user_instansi, pass_instansi, dan alamat. Pada tabel instansi mempunyai primary key yaitu id_instansi. c) Tabel Kamus. Tabel kamus berfungsi untuk meyimpan data kata yang menghubungkan antara Dinas Perhubungan, Dinas Pariwisata dan Kebudayaan, Dinas Pemukinan dan Prasarana Wilayah. Pada tabel Kamus id_kamus adalah Primary key dan id_instansi sebagai Foreign Key. d) Tabel Keluhan. Tabel keluhan berfungsi untuk menyimpan dan mengakses data yang berhubungan dengan data keluhan masyarakat seperti id_keluhan, judul, keterangan, gambar, latitude, longitude, waktu_keluhan, id_user, id_instansi. Pada tabel ini mempunyai id_keluhan sebagai Primary key, id_user dan id_instansi sebagai Foreign key. e) Tabel Respon. Tabel respon berfungsi untuk menyimpan dan mengakses data yang berhubungan dengan data respon seperti id_respon, 
status, pesan, gambar, waktu_respon, id_keluhan. Pada tabel respon mempunyai primary key yaitu id_respon, dan foreign key yaitu id_keluhan. Berikut ada lah bentuk tabel pada Tabel Respon. f) Tabel User. Tabel user berfungsi untuk menyimpan dan mengakses data yang berhubungan dengan olah data user seperti id_user, email, pass_user, aktif. Pada tabel respon mempunyai primary key yaitu id_user. Dari tabel-tabel dalam sistem ini dapat ditransformasikan ke himpunan tabel-tabel yang saling berhubungan, yang menunjukkan adanya hubungan antara sejumlah entitas yang berasal dari himpunan entitas yang berbeda. Pada relasi antar tabel juga akan diperlihatkan bagaimana kardinalitas antara entitas satu dengan entitas lainnya yang saling berhubungan. Relasi antar tabel dari Aplikasi ini bisa dilihat pada Gambar 12.

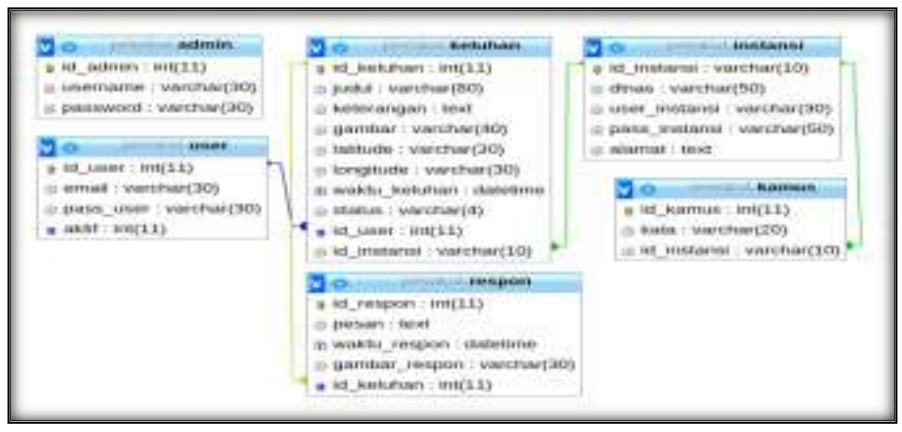

Gambar 12 Relasi Antar Tabel

4. Implementasi dan Pengujian

4.1 Perangkat Keras yang Digunakan

Penyelesaian program ini dibuat dengan didukung oleh komponen perangkat keras dengan spesifikasi sebagai berikut :

1. Komputer Pesonal dengan processor Intel(R) Core(TM) i3 CPU 1.7GHz.

2. RAM 2 GB.

3. VGA $500 \mathrm{MB}$.

4. Handphone dengan sistem operasi Android

\subsection{Perangkat Lunak yang Digunakan}

Untuk merancang aplikasi ini dibutuhkan beberapa perangkat lunak pendukung. Rincian kebutuhan antara lain:

1. Sistem Operasi yang digunakan adalah Microsoft Windows 8.1 Pro 64-bit.

2. Database menggunakan SQLite.

3. Bahasa Pemograman yang digunakan adalah Java dan PHP.

4. Program yang digunakan untuk membangun aplikasi adalah Android Studio IDE dan NetBeans IDE.

\subsection{Implementasi Aplikasi}

Pada sub bab ini dibahas mengenai user interface yang dapat dilakukan oleh user dan admin, diantaranya:

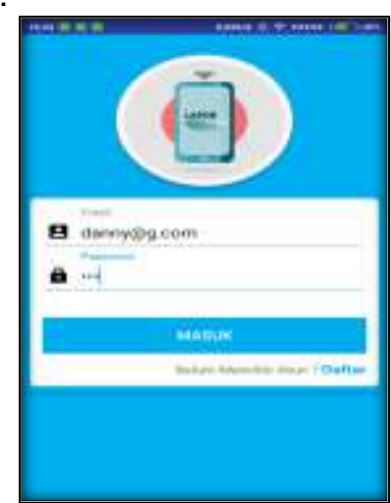

Gambar 13 Halaman Login

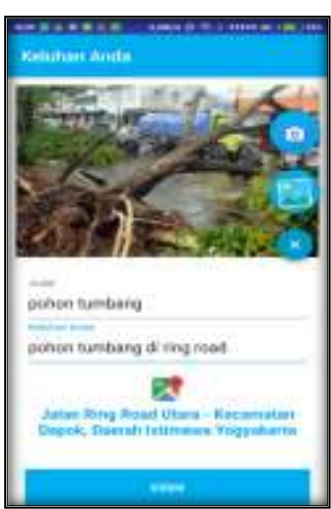

Gambar 14 Halaman Upload Keluhan 
Pada Gambar 13, user melakukan login untuk memperoleh hak akses masuk aplikasi. Dan pada Gambar 14, user dapat mengirimkan keluhannya berupa gambar, judul keluhan, rincian keluhan, serta lokasi keluhan.

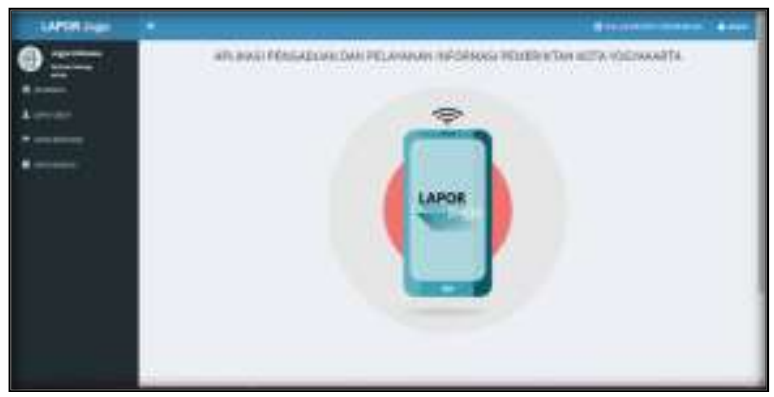

Gambar 15 Halaman Login

Pada Gambar 15 merupakan tampilan menu beranda admin, yang dimana admin dapat mengolah data user, data instansi, dan data kamus.

\section{PENUTUP}

\subsection{Kesimpulan}

Berdasarkan hasil penelitian yang dilakukan, dapat diambil kesimpulan bahwa telah berhasil dibangun sebuah aplikasi mobile yang dapat membantu pengguna yaitu masyarakat kota Yogyakarta untuk melaporkan keluhan atau memberikan kritik dan saran ke Dinas Pemerintahan Kota Yogyakarta dengan efisien. Aplikasi ini mengoptimalkan sistem Unit Pelayanan Keluhan dan Informasi (UPIK). Selain itu implementasi metode Brute Force membantu sistem dalam mencari dinas yang sesuai dengan keluhan pengguna.

\subsection{Saran}

Dari penelitian yang telah dilakukan berbagai masalah yang dapat diselesaikan telah dijelaskan pada bagian kesimpulan. Tetapi pengembangan dari sistem ini juga masih memiliki banyak kekurangan. Oleh karena itu, masukan yang mungkin dapat diterapkan untuk pengembangan sistem lebih lanjut adalah sebagai berikut:

1. Metode brute force pada sistem ini masih memiliki banyak kekurangan. Perlu adanya penambahan atau pengembangan dengan menggunakan metode lain.

2. Perlu adanya fitur-fitur yang lebih menunjang sistem, seperti fitur comment, share, rating pada setiap keluhan.

3. Semakin beragamnya sistem operasi pada smartphone saat ini, perlu adanya pengembangan sistem yang terintegrasi dengan sistem operasi lainnya.

\section{DAFTAR PUSTAKA}

A. Suhendar, Hariman Gunadi, 2002, Visual Modeling Menggunakan UML dan Rational Rose, Informatika Bandung.

Anonim, developer android. (http://developer.android.com/google/playservices/index.html, diakses : 5 April 2016)

Arbie. 2004. Manajemen Database dengan MSSQL. Jilid I Yogyakarta : Andi Yogyakarta.

Juman, Kundang. Sejarah Android, (http://kundang.weblog.esaunggul.ac.id, diakses tanggal 10 November 2017)

Nicolas Gramlich, Andbook : Android Programming, (http://andbook.anddev.org, diakses tanggal 30 Maret)

Sembiring, Krisantus. 2006. Penerapan Mobile Government di Indonesia. Institut Teknologi Bandung

Schmuller, Joseph. 1999. Sams Teach Yourself UML in 24 Hours. Pearson Education, Inc. 